\title{
A PRÁTICA CULTURAL DE CONSTRUÇÃO DO MATAPI: \\ possibilidades para o ensino de geometria utilizando o Geogebra
}

THE CULTURAL PRACTICE OF THE MAKING OF MATAPI:

possibilities for the teaching of geometry through the Geogebra

\author{
Renata Lourinho da Silva ${ }^{1}$ \\ Denivaldo Pantoja da Silva ${ }^{2}$ \\ Maria Katiane Miranda Ribeiro ${ }^{3}$
}

\section{Resumo}

Neste artigo, apresentamos uma experiência com a construção do artefato matapi, utilizando o software Geogebra, a partir de sua construção física in loco. Foi desenvolvida no curso de formação de professores para a educação do campo, que abordou o tema: Construção e uso do matapi: diálogos entre tempo escola e tempo comunidade. Nosso objetivo é apresentar possibilidades para abordar algumas noções da geometria em sala de aula, partindo da construção do matapi, utilizando o Geogebra como instrumento didático. Para alcançar esse objetivo, apresentamos algumas imagens do matapi, que foi construído no local, para, em seguida, representá-lo no ambiente virtual com auxílio do software. Os resultados mostram que se pode promover a construção de algumas noções matemáticas da geometria plana e espacial a partir da construção física do artefato.

Palavras-chave: Artefato cultural. Geometria plana. Tecnologia. Geogebra.

\begin{abstract}
In this study, we describe an experience with the making of matapi handicraft by using the Geogebra software from its physical construction in loco; and it was developed in the teacher training

\footnotetext{
${ }^{1}$ Doutora em Educação Matemática e Ciências, pelo Instituto de Educação Matemática e Científica da Universidade Federal do Pará. E-mail: renatalourinhodasilva@gmail.com

${ }^{2}$ Doutor em Educação em Ciências e Matemáticas pelo Instituto de Educação Matemática e Científica (IEMCI) da Universidade Federal do Pará. Docente da Faculdade de Matemática (FAMAT), Campus Tocantins/Cametá. E-mail: denivaldo@ufpa.br

${ }^{3}$ Especialista em Ensino de Matemática para o Ensino Básico/CCAME e licenciada em Matemática pela Universidade Federal do Pará. E-mail: katycell@ hotmail.com
} 
A prática cultural da construção do Matapi: possibilidades para o ensino de Geometria utilizando o Geogebra

course for rural education, which addressed the issue: Making and use of matapi: pedagogy of alternation-based dialogues. The aim is to present possibilities to approach some geometry basics in classroom, from the making of matapi by using the Geogebra as a teaching tool. In order to achieve this aim, we present some images of matapi which was built in loco, and then it was represented in a virtual environment with the aid of that software. The results reveal that it is possible to promote the construction of mathematics basics of plane and spatial geometry from its physical construction.

Keywords: Cultural handicraft. Plane geometry. Technology. Geogebra.

\section{Introdução}

Este trabalho apresenta uma experiência vivenciada por Amanda ${ }^{4}$ como participante de um curso de extensão universitária com o tema "Construção e uso do artefato matapi: diálogos entre tempo escola e tempo comunidade", desenvolvido para a formação continuada de professores em educação do campo, em que se valorizou a forma artesanal de construção do matapi 5 .

O matapi é um tipo de artefato cultural constituído de cortes - denominado talas - do material que envolve a planta nativa da região amazônica tocantina, denominada Jupaty ${ }^{6}$, utilizado para captura do camarão ${ }^{7}$. O desenvolvimento da formação continuada de professores, por meio do curso extensionista universitário, constituiu-se como campo de pesquisa empírica do projeto de tese de doutoramento.

O curso contou com a participação de dois produtores artesanais de matapi residentes na comunidade de Pacui de Cima, situado no município de Cametá, no estado do Pará, sendo um deles considerado experiente, com mais de quarenta anos trabalhando na produção de artefato des-

\footnotetext{
$\overline{{ }^{4} \text { Nome fictício para }}$ referir à personagem a qual trata a experiência relatada.

${ }^{5}$ Objeto construído pelas pessoas da comunidade para fins de pesca;

6 "Talas de jupati (Raphiataedigera)" (MORAES, 2005, p.66).

${ }^{7}$ Camarão da Amazônia espécie Macrobrachium amazonicum (MORAES-RIODADES, 2005).
} 
A prática cultural da construção do Matapi: possibilidades para o ensino de Geometria utilizando o Geogebra

sa comunidade, que conduziu o processo de construção para os participantes, acompanhados pelo pesquisador.

No decorrer do curso, ouvirmos alguns relatos dos produtores de matapi e percebemos que se tratava de uma prática desvalorizada. A maioria dos jovens das comunidades ribeirinhas do município de Cametá, no Pará, não sabe e nem se interessa em aprender a construir o artefato, consequentemente, aos poucos, esse artefato segue desaparecendo.

Notamos, também, que há comercialização do matapi, vendido nas comunidades circunvizinhas por um preço muito baixo, desvalorizando deste modo, o trabalho que demanda para ser construído - uma vez que por trás dessa construção, tem todo um processo inicial que consiste em: fazer a coleta do material das talas, cortar a fibra e secar ao sol por uma semana, depois, limpar a fibra e cortá-la para confeccionar as talas para construir o matapi - tarefa que exige determinadas habilidades, entre elas, força e equilíbrio, distintas posições do corpo de quem está construindo, para fixar as talas de modo que fiquem alinhadas.

Nesse sentido, podemos dizer que a prática cultural de construção do matapi realizada pelos produtores da comunidade do Pacuí de Cima, configura-se como uma prática complexa, por envolver várias tarefas e, para cada uma, mobiliza-se determinada técnica, no sentido dado por Chevallard (1999), constitui-se o bloco do saber prático, que se justifica por si mesmo, por isso, chamadas auto-tecnológicas.

No primeiro momento, nossa personagem Amanda, teve dificuldades em tecer o fio entre as talas, pois ainda não tinha habilidade com a construção, porque existem várias técnicas que podem ser utilizadas no momento de construir, como, por exemplo, encontrar um modo de posicionar seu corpo para tecer adequadamente. Mas, cada encontro foi um aprendizado, adquirindo-se a técnica adequada para a construção - isso aconteceu após conhecer cada passo da mesma. Os detalhes dessa cons- 
A prática cultural da construção do Matapi: possibilidades para o ensino de Geometria utilizando o Geogebra

trução possibilitam que sejam trabalhadas noções matemáticas da Geometria como, por exemplo, o paralelismo de retas.

Por outro lado, o uso do matapi tradicional para a captura de camarões é uns dos meios de sustento de famílias ribeirinhas. A matéria prima de construção é retirada da natureza, sendo essa prática repassada de geração para geração, conforme tratou Silva, Ribeiro e Rocha (2017).

Portanto, o objetivo deste trabalho é apresentar possibilidades para abordar algumas noções da geometria em sala de aula partindo da construção do matapi, utilizando o Geogebra como instrumento didático, enfatizando a experiência vivenciada por Amanda durante a formação continuada.

\section{Metodologia e possibilidades e ensino}

Para o desenvolvimento metodológico desse trabalho, apresentaremos algumas imagens do matapi construídos durante o curso de formação, como, por exemplo, a confecção de partes do matapi chamados de "tapete" e "língua" e também os passos da construção do artefato, em ambiente virtual, utilizando como instrumento didático o software Geogebra, fazendo analogia com modelos de figuras geométricas como o cilindro reto e equilátero.

A construção do matapi inicia-se, primeiramente, pelo "pari" - denominação atribuída à parte lateral do matapi - que é dividido em quatro tecimentos - denominados, pelos produtores da comunidade de Pacuí de Cima, de "teçumes". Em seguida, fecha-se o pari, que renomeamos por "tapete"; posteriormente, se insere quatro rodas de sustentação, feitas de cipó. Após a inserção das rodas, faz-se a língua, seguida pelo enchulia- 
A prática cultural da construção do Matapi: possibilidades para o ensino de Geometria utilizando o Geogebra

mento $^{8}$ e, para finalização, constrói-se a janela, que será utilizada para fixar as iscas e também para retirada dos camarões capturados pelo artefato.

As figuras 1 e 2 seguintes mostram resumidamente duas etapas da execução desse processo, os participantes fazendo a tessitura do pari, após orientação do instrutor.

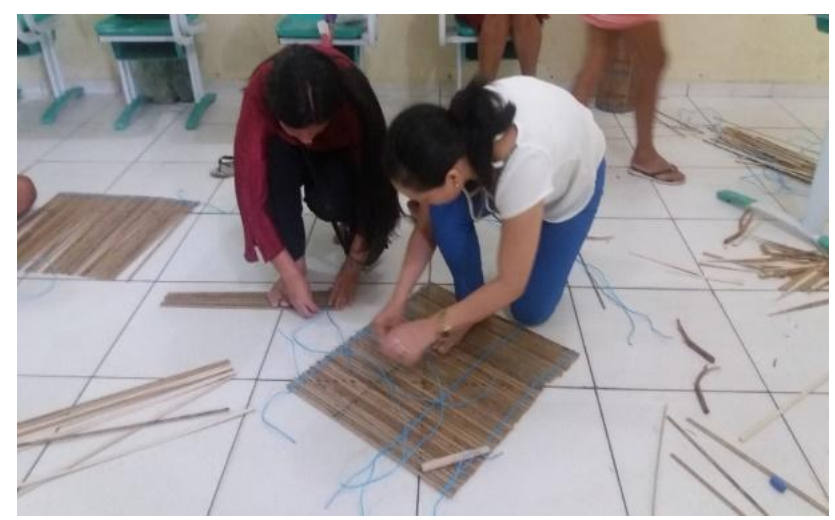

Figura 1 - Construção do Pari

Fonte: Autores, 2019

Finalizada a construção do pari, segue-se a construção da língua do matapi.

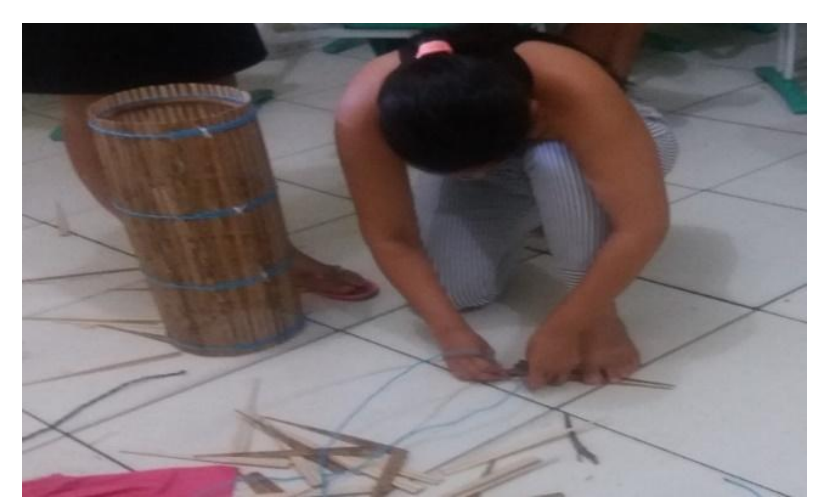

Figura 2 - Construção da Língua

Fonte: Autores, 2019

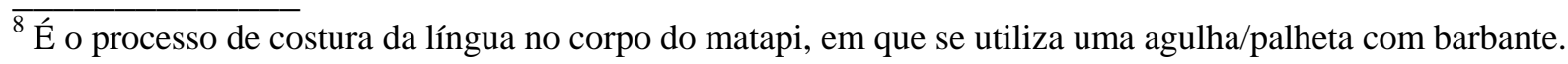


A prática cultural da construção do Matapi: possibilidades para o ensino de Geometria utilizando o Geogebra

A partir desse ponto, segue a finalização do matapi. O artefato construído por Amanda apresentou as seguintes medidas: comprimento 55 centímetros por 65 centímetros de tapete; com 44 talas e distância de $2 \mathrm{~mm}$ entre as latas; o comprimento da língua $23 \mathrm{~cm}$; o diâmetro maior da entrada dos camarões $21 \mathrm{~cm}$; o diâmetro menor $2,5 \mathrm{~cm}$; a distância entre os cones (linguas) $13 \mathrm{~cm}$ e a espessura da tala $1,8 \mathrm{~mm}$. Na figura 3 , os matapis construídos.

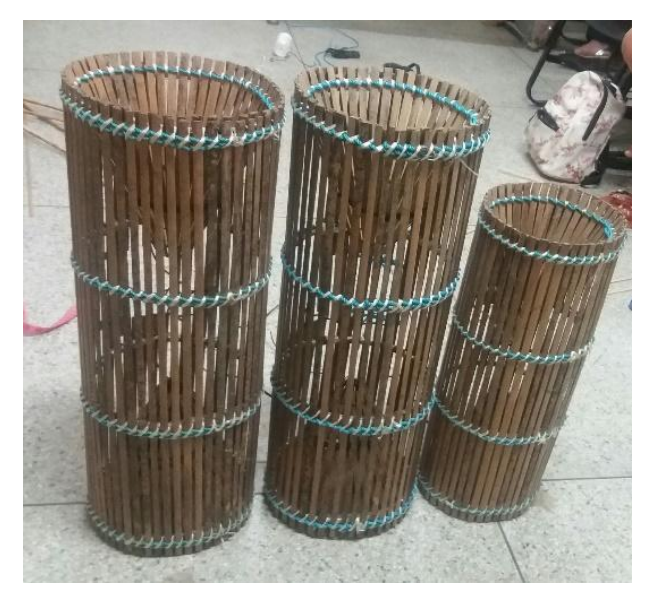

Figura 3 - Matapis finalizados Fonte: Autores, 2019.

Após a construção concretamente finalizada, Amanda passou a construir os elementos constituintes do matapi usando o software Geogebra, ficando evidente o surgimento de alguns entes geométricos: cone, cilindro, retângulo, retas etc. e que podem ser tratadas nas aulas. A nova construção do matapi, obtida com o Geogebra, assemelhou-se com a forma de um cilindro circular reto. Amanda fez a planificação do artefato no referido software em conjunto com o produtor sênior de matapi. A figura 4 seguinte mostra esse gesto. 
A prática cultural da construção do Matapi: possibilidades para o ensino de Geometria utilizando o Geogebra

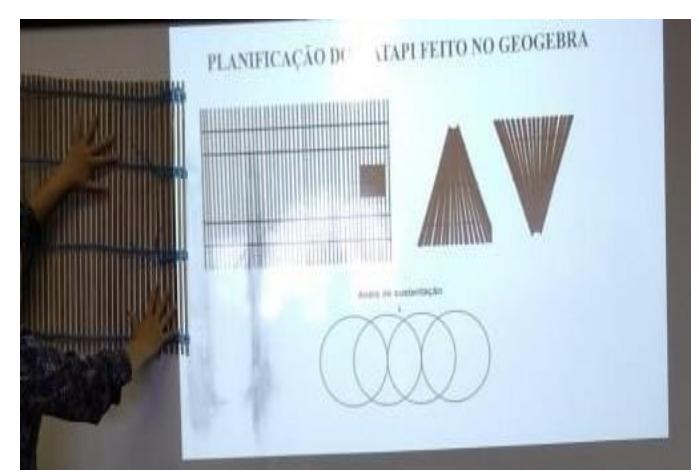

Figura 4 - Planificação do matapi no Geogebra

Fonte: Autores, 2019

Isso mostra a possibilidade do uso do software como instrumento didático para reprodução da pratica cultural de construção do matapi no ambiente de geometria dinâmica, mostra, ainda, a potencialidade didática de trabalhar as figuras geométricas que são modelos, a partir ds prática cultural. Para evidenciar essa potencialidade, a construção do matapi que foi realizada obedecendo os seguintes passos:

\section{$1^{\circ}$ Passo: Construção do Tapete}

Essa etapa, na prática, exige precisão para manter as talas adequadamente firmes e paralelas, no Geogebra essa tarefa se otimiza, como podemos observar nas figura 5, 6 e 7 que mostram a sequência da construção.

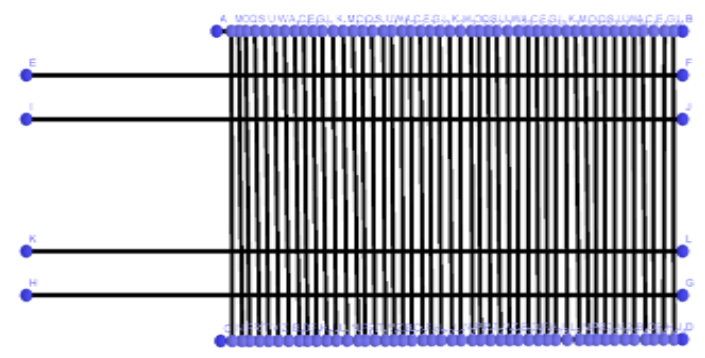

Figura 5 - Construção do tapete (1)

Fonte: Autores, 2019 

possibilidades para o ensino de Geometria utilizando o Geogebra

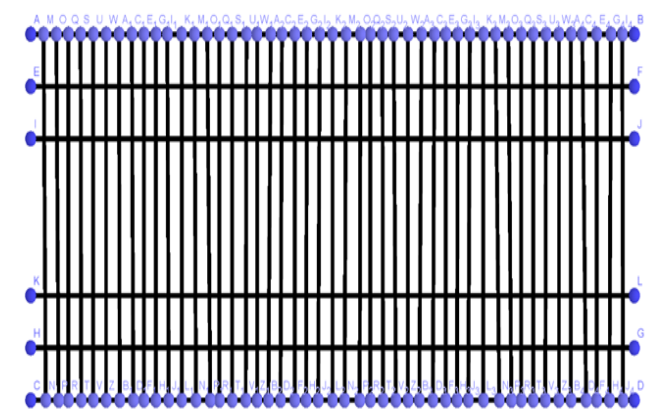

Figura 6 - Construção do tapete (2)

Fonte: Autores, 2019

Em continuação, a figura 7 apresenta o processo de construção do tapete finalizado.

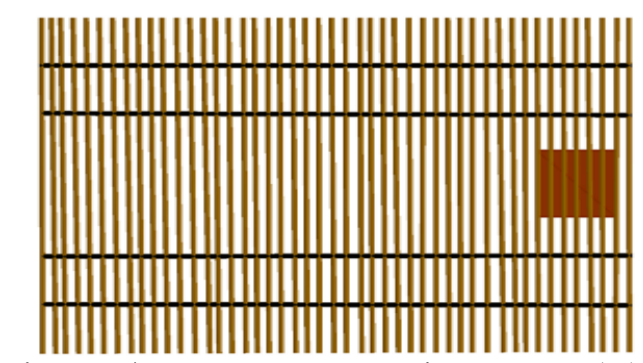

Figura 7- Construção do tapete (3)

Fonte: Autores, 2019

$2^{\circ}$ Passo:Construção da Lingua

Neste caso, as figuras seguintes resumem e ilustram etapas dos procedimentos adotados na construção de outro componente essecial do matapi, buscando mostrar mais ou menos como de fato acontece. 
A prática cultural da construção do Matapi: possibilidades para o ensino de Geometria utilizando o Geogebra

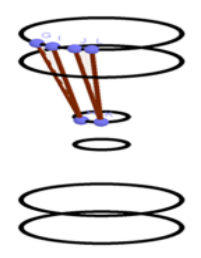

Figura 8 - Inserção das Rodas (1)

Fonte: Autores, 2019

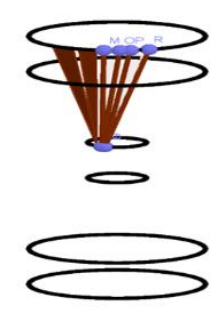

Figura 9 - Inserção das Rodas (2)

Fonte: Autores, 2019

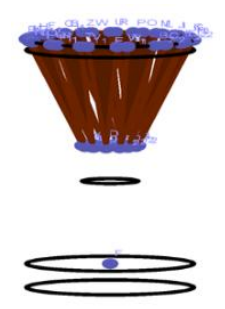

Figura 9 - Construção da Língua (3)

Fonte: Autores, 2019

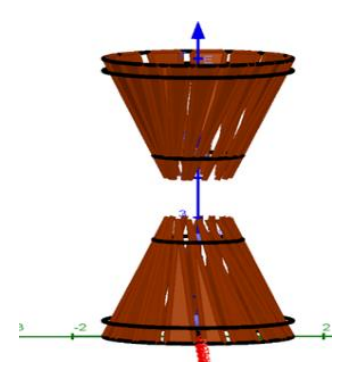

Figura 9 - Construção da Língua (5)

Fonte: Autores, 2019 
A prática cultural da construção do Matapi: possibilidades para o ensino de Geometria utilizando o Geogebra

$3^{\circ}$ Passo: Finalização do matapi

Finalmente, as figuras 11 e 12 mostram os matapis prontos para uso construídos no Geogebra. Identificam-se alguns componentes importantes.

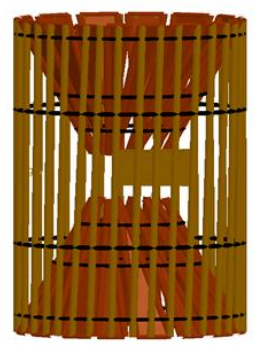

Figura 12 - Matapi fizalizado tipo 1

Fonte: Autores, 2019

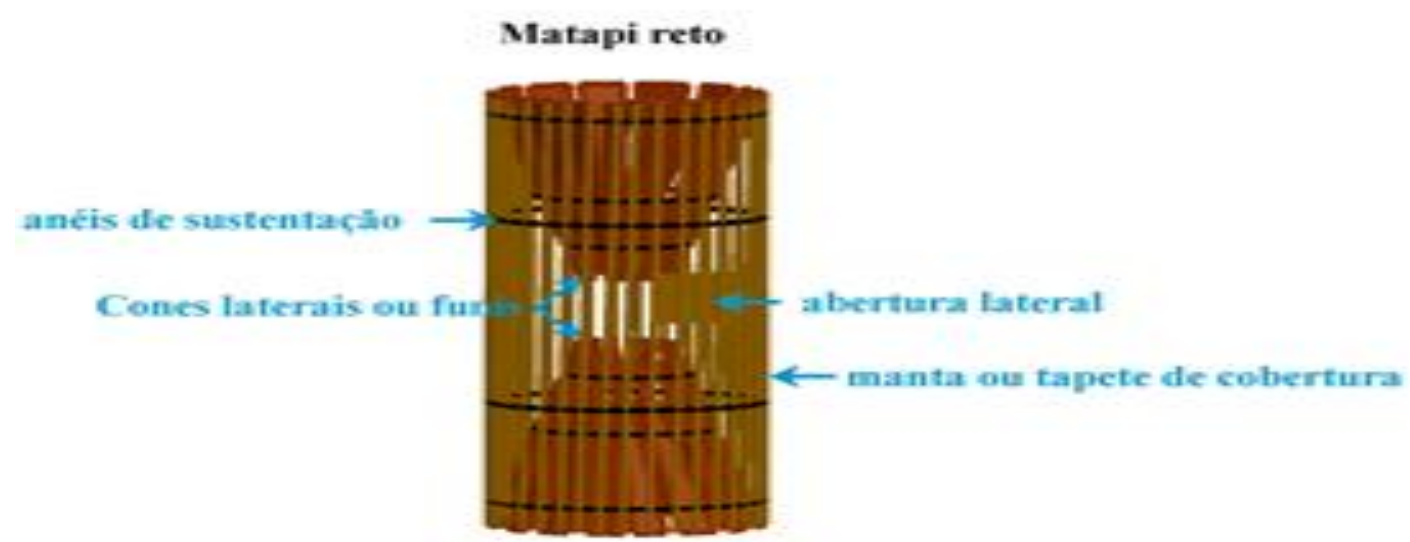

Figura 13 - Matapi

Fonte: Autores, 2019 
A prática cultural da construção do Matapi: possibilidades para o ensino de Geometria utilizando o Geogebra

Essa descrição apresentada ilustrou a experiência vivenciada por Amanda no curso de formação continuada. Além disso, identificou-se que é possivel fazer o tapete no programa Geogebra de duas formas: a primeira, no formato retangular, que ao ser fechado tem a forma de um cilindro circular reto; a segunda, no formato quadrado, gera um cilindro equilátero - esse formato quadrático foi sugerido no início do curso por orientação acadêmica. Aqui focalizamos o cilindro reto.

De acordo com Caltaldo (2009),

Cilindro reto: Chamamos de secção meridiana de um cilindro à interseção do cilindro com o plano que contém o seu eixo. As secções meridianas de um cilindro são paralelogramos (retângulos ou não). Pois, para um cilindro circular reto, as secções meridianas são retângulos com medidas $h$ (altura) e 2r (diâmetro da base).Cilindros equilátero: Um cilindro e chamado equilátero se ele for reto e se sua secção meridiana for quadrada (CALTALDO, 2009, pp.109119).

Enfim, para Dante (2005, p. 383), a Geratriz do cilindro entende-se: "os segmentos paralelos ao eixo, cujas extremidades são pontos das circunferências das bases, são chamadas geratrizes do cilindro", e essas geratrizes são responsáveis por determinar a construção do cilindro reto e equilátero.

\section{Considerações finais}

Nossa preocupação, neste artigo, foi apresentar, de forma panorâmica, como o desenvolvimento de uma prática sociocultural pode viabilizar estudos de objetos de ensino, explorando suas propriedades e relações, a partir da prática até a formalização de modelos geométricos traba- 
A prática cultural da construção do Matapi: possibilidades para o ensino de Geometria utilizando o Geogebra

lhados nas aulas de geometria, propondo como alternativa o uso de softwares educacionais específicos, em nosso caso, o Geogebra.

Percebemos, durante o desenvolvimento do curso de extensão, especificamente, desde o momento de construção do matapi, até a finalização do mesmo, possibilidades didáticas para tratar potencialmente algumas noções e relações da geometria utilizando o Geogebra, a partir da prática cultural de fabricação do matapi. Por exemplo, as relações entre as formas geométricas planas e espaciais, em que, na construção do tapete, representa uma forma geométrica plana, bidimensional e, ao fechálo, se transforma em objeto espacial, com três dimensões.

A partir do domínio da prática, a construção do matapi concreto, promoveu uma experiência que possibilitou vivenciar o recurso utilitário de pesca de camarão, que é uma prática complexa por envolver várias técnicas, tais como a posição que se deve ter, como se deve fazer o tecimento do tapete, da língua, a construção da janela, lugar em que se coloca a isca.

Desse modo, Amanda como professora de Matemática, percebeu a possibilidade de uso em sala de aula, então, questionou: como poderia explorar os saberes envolvidos nessa prática nas aulas de Matemática? Uma resposta desafiadora que encaminhou foi reconstruir os saberes em ambiente virtual de geometria dinâmica, especificamente o uso do software Geogebra.

Destacamos que a construção do matapi, no ambiente virtual, com o Geogebra como transposição didática, possibilitou uma melhor compreensão de algumas noções de geometria espacial, cilindro reto e equilátero, sendo determinados por suas geratrizes. Deste modo, torna-se um recurso didático eficaz para trabalhar noções de geometria plana e espacial, em que os alunos, através do processo de construção, identificam os elementos e relações estabelecidas nos objetos estudados. 
A prática cultural da construção do Matapi: possibilidades para o ensino de Geometria utilizando o Geogebra

Portanto, notamos que o Geogebra é um programa dinâmico, com potencial didático, que se mostrou ser possível de uso nas aulas de geometria, contribuindo significantemente para melhoria do ensino de Matemática, em particular, de geometria, pois, com ele é possivel se explorar a construção de vários objetos da prática social escolar, especificamente o que exploramos, com a prática cultural de construção do matapi, a ressignificação de métodos de ensino.

\section{Referências}

CALTALDO, Edison Luiz Ferreira. Licenciatura em Matemática, volume 2: Geometria I. 3. ed. Rio de Janeiro: fundação CECIERJ, 2009. 109,119,129 p.

CHEVALLARD, Yves. El análise de las práticas docentes en la teoria antropológica de lo didático. Recherches en Didactique des mathématiques, v. 19, n. 2, p. 221-266, 1999.

DANTE, Luiz Roberto. Matemática, volume único. 1. ed. São Paulo: Ática, 2005.

MORAES, Sergio Cardoso de. Saberes da pesca: uma arqueologia da ciência da tradição. 2005. Tese (Doutorado em Educação) - Universidade Federal do Rio Grande do Norte, Natal, 2005.

Disponivel em:ftp://ftp.ufrn.br/pub/biblioteca/ext/bdtd/SergioCM.pdf. Acesso em: 20 fev. 2018.

MORAES-RIODADES, Patrícia M. C. Cultivo do camarão-da-amazônia, Macrobrachium amazonicum (Heller, 1862) (Crustacea, Decapoda, Palaemonidae) em diferentes densidades: fatores ambientais, biologia populacional e sustentabilidade econômica. 2005. Tese (Doutorado em Aquicultura) - Centro de Aquicultura, Universidade Estadual Paulista, Jaboticabal, 2005.

Disponivel em: https://repositorio.unesp.br/handle/11449/144173. Acesso em: 10 jun. 2019.

SILVA, Jane Cristina da; Ribeiro, Ivo Antônio; Rocha, Maria Lúcia Pessoa chaves. Construção e uso do matapi: um estudo etnomatemático. CONGRESSO INTERNACIONAL DE ENSINO DA MATEMÁTICA, 7., 2017. Anais... Canoas: ULBRA, 2017. 